\title{
Global environment- and space-richness ranking relationships: The effects of interaction and high-order terms of explanatory variables
}

\author{
Youhua Chen \\ Department of Renewable Resources, University of Alberta, Edmonton, Canada; youhua@ualberta.ca, haydi@126.com
}

Received 12 August 2013; revised 12 September 2013; accepted 18 September 2013

Copyright (c) 2013 Youhua Chen. This is an open access article distributed under the Creative Commons Attribution License, which permits unrestricted use, distribution, and reproduction in any medium, provided the original work is properly cited.

\section{ABSTRACT}

In the present study, the interplay and higherorder terms of environmental and spatial variables are considered to evaluate the relations of environment- and space-species richness rankings at global scale. Three taxonomic groups composed of mammals, birds and amphibians were analyzed for the study. The $k$-means clustering method was introduced for richness rankings detection and analysis from published digital maps; and simple regression analysis and AIC criteria were used for identifying most important correlated explanatory variables. When comparing each single variable, I found that latitude was the most important one influencing global vertebrate richness rankings. When only considering environmental variables, I found that precipitation was the only predictor of vertebrate richness rankings. However, when the interaction and high-order terms of different independent variables were considered, it was found that the interaction between latitude and temperature could better explain the global bird richness ranking, while the second-power effect of latitude was the best predictor for amphibian and mammalian richness rankings, as evidenced by the AIC model selection and comparison among the regression models. In conclusion, the inclusion of high-order and interaction terms of environmental and spatial variables could offer more insights into the understanding of global species diversity patterns.

Keywords: Global Species Distribution; Nonlinearity; Richness Ranking; Diversity Mapping; Environment Envelope

\section{INTRODUCTION}

Environment-species richness relationships have been broadly investigated [1-4]. Typically, water availability and energetic constraints were the two widely referred mechanisms to explain the global and regional scales of species diversity patterns. Space, indicated by geographic locations, was also recognized as an important mechanism. Usually the influence of space on species diversity was named as spatial autocorrelation [5], which stated that two locations have high similarity of species due to their close distance.

However, the effects of interaction and high-order terms of environmental and spatial variables on influencing species richness seemed never investigated as far as I know. As for varying spatial scales, the coupling of different factors to affect species diversity and distribution should be quite usual. Thus, it might be valuable to consider the effects of interplay and higher-order terms of different environmental and spatial variables on species richness and provided a more general framework of environment/space-richness relationships.

Like species-area and endemism-area relationships [6], if I could find out a universe form of environment/ space-richness relationship at global/regional scales, I may be better to quantify the impacts of global climate change on influencing biodiversity and estimate species loss caused by the climate change.

In this brief report, I used global distributions of birds, mammals and amphibians to analyze the relationship of environment/space and species richness rankings by considering interaction and high-order terms of environmental and spatial variables. I will show why it is necessary to introduce the interaction and high-order terms of independent variables.

\section{MATERIALS AND METHODS}

The richness patterns of worldwide birds, mammals, 
and amphibians were estimated and standardized using the published digital maps. The referred published digital maps were collected from the previous literature [7]. Extraction of species richness at each grid cell is very hard since the digitized map is not accurate due to limited resolution and the colors for representing different species richness are difficult to match. Thus, I must consider an alternative option, which is the very reason why I used richness ranking as the proximity to study the relationship of environment and diversity [8,9].

$k$-means clustering method was employed to obtain 15 classes of species richness based on the digitized colors [9]. Each class was then checked carefully by eyes to obtain the richness rankings when compared the clustered grid cells with those present in the published literature [7]. Some classes only contained grid cells that are hard to determine their richness rankings or located in islands and edges of territory were no more considered. As such I obtained 12 rankings for the birds, and 9 rankings for amphibians and 8 for mammals respectively. The clustering algorithm was implemented using $\mathrm{R}$ software [10].

To avoid artifacts, I also consider different richness groups using $k$-means clustering. However, I found the results from the 10,30 , and 50 classes of richness for different taxonomies were basically identical to those for the 15-class of species richness orderings, after removing some classes that only contained grid cells which were located in islands and edges of territory [9].

The environmental variable data were gathered through the website WorldClim (http://worldclim.org). The variables temperature $(\mathrm{T})$, precipitation $(\mathrm{P})$, and elevation (E) were the ones chosen by my study.

Thereby, I considered three environmental variables and two spatial variables (latitude and longitude) and evaluated their associations with global vertebrate richness rankings. In particular, their interaction and highorder terms (up to the power of 2) were considered. In a summary, the series of variables used was described in Table 1.

\section{RESULTS}

\subsection{The Influence of a Single Environmental or Spatial Variable}

I identified that two variables latitude and precipitation were the most correlated ones to all the three vertebrate richness rankings using linear regression analysis (Figure 1, Table 2). For all the three taxonomic groups, spatial influence was always higher than environmental influence on determining richness rankings at worldwide scale. For birds, spatial influence from latitude (adjusted $\mathrm{R}^{2}=0.2227 ; \mathrm{P}=0$; AIC $=211612.5$ ) was stronger than the environmental influence from precipitation (adjusted $\mathrm{R}^{2}=0.09876 ; \mathrm{P}=0$; AIC $=218171.9$, not showed in Table 2). For amphibians, the model for latitude had the adjusted $\mathrm{R}^{2}=0.27 ; \mathrm{P}=0$; AIC $=184417.4$. For mammals, the model for latitude had the adjusted $\mathrm{R}^{2}=0.194 ; \mathrm{P}=0$; AIC $=157903.4$ (Table 2).

\subsection{The Influence of Interaction among Environmental and Spatial Variables}

I found that the interaction between latitude and tem-

Table 1. Summary of various environmental and spatial variables used in the linear regression analysis.

\begin{tabular}{cc}
\hline Variables & Meanings \\
\hline$T, T^{2}$ & Mean annual temperature and second-order effect \\
$P, P^{2}$ & Annual precipitation and second-order effect \\
$E, E^{2}$ & Elevation and second-order effect \\
Lat, Lat $^{2}$ & Latitude and second-order effect \\
Long, Long $^{2}$ & Longitude and second-order effect \\
$T \times P$ & Interaction of temperature and precipitation \\
$T \times E$ & Interaction of temperature and elevation \\
$E \times P$ & Interaction of elevation and precipitation \\
Lat $\times P$ & Interaction of latitude and precipitation \\
Lat $\times T$ & Interaction of latitude and temperature \\
Lat $\times E$ & Interaction of latitude and elevation \\
Long $\times P$ & Interaction of longitude and precipitation \\
Long $\times T$ & Interaction of longitude and temperature \\
Long $\times E$ & Interaction of longitude and elevation \\
\hline
\end{tabular}

Table 2. Best selected models for single variable, interaction of variables and second-power terms of variables. Data in bold indicated the model was the best among the three categories of variables.

\begin{tabular}{|c|c|c|c|c|c|c|}
\hline \multirow{2}{*}{$\frac{\text { Categories of variables }}{\text { Statistics }}$} & \multicolumn{2}{|c|}{ Single variable } & \multicolumn{2}{|c|}{ Interaction of variables } & \multicolumn{2}{|c|}{ Second power of variables } \\
\hline & adjusted $\mathrm{R}^{2}$ & AIC & adjusted $\mathrm{R}^{2}$ & AIC & adjusted $\mathrm{R}^{2}$ & AIC \\
\hline Birds & 0.099 & 218171.9 & 0.224 & 211543.9 & 0.142 & 216006 \\
\hline Amphibians & 0.27 & 184417.4 & 0.257 & 185091.7 & 0.356 & 179543.8 \\
\hline Mammals & 0.194 & 157903.4 & 0.208 & 157174.9 & 0.293 & 152331.7 \\
\hline
\end{tabular}




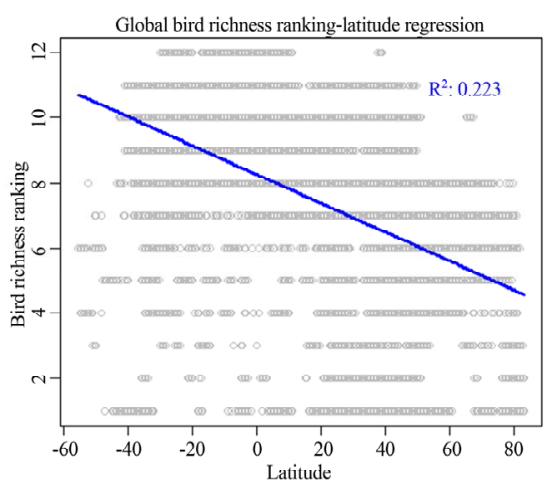

(a)

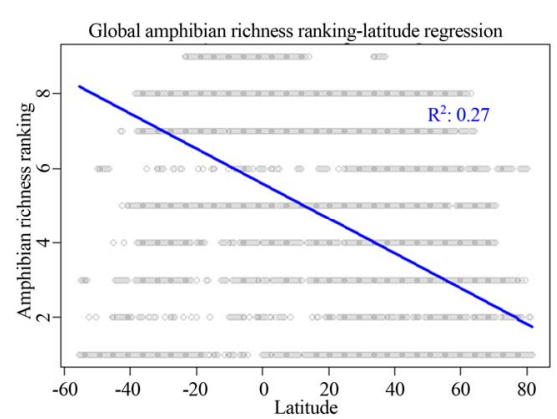

(d)

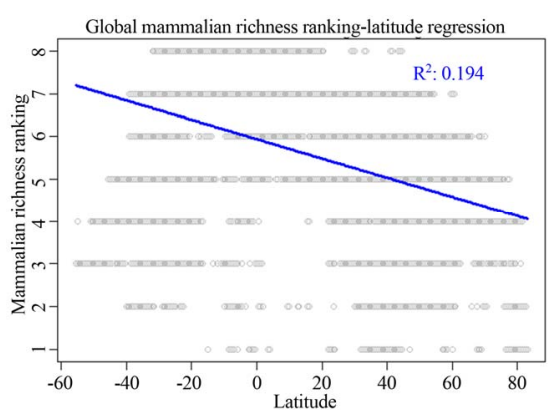

(g)

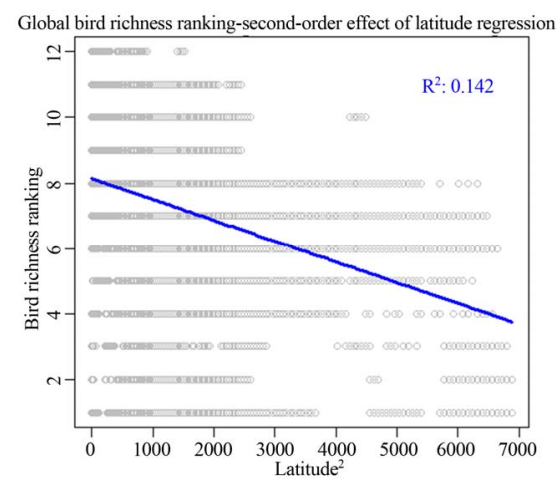

(b)

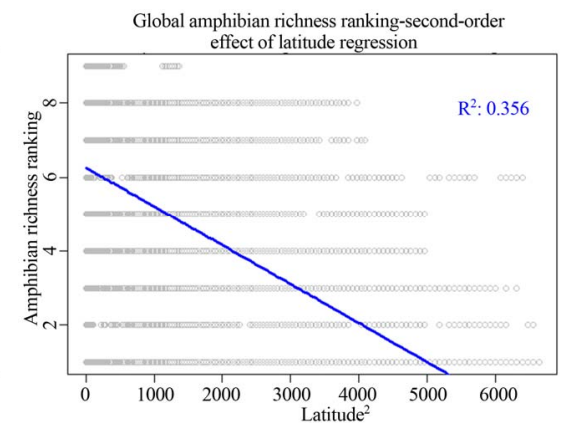

(e)

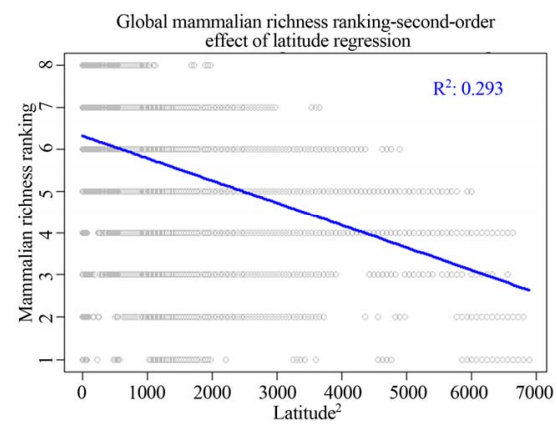

(h)

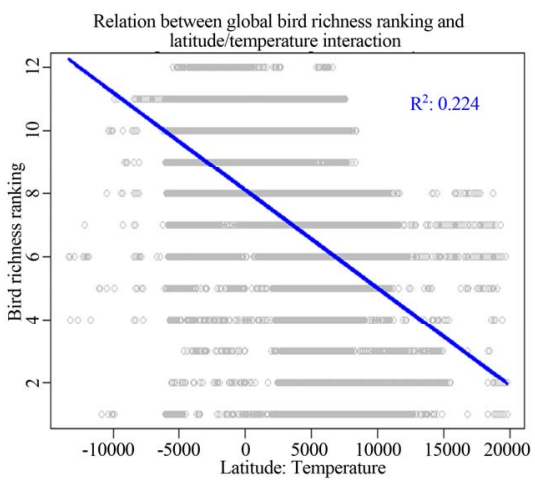

(c)

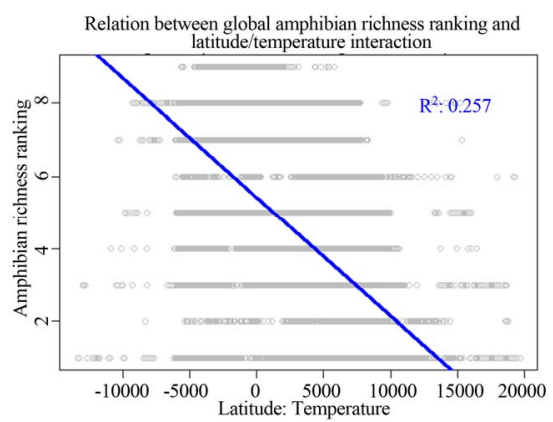

(f)

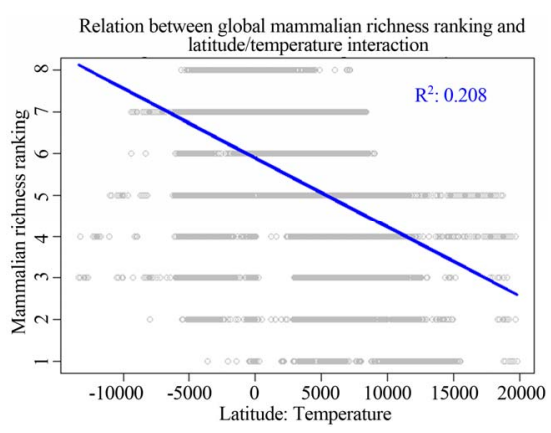

(i)

Figure 1. Most significant regressions between vertebrate species richness rankings and environmental/spatial variables. All regressions have $P=0$. (a), (d), (g) reflected the most correlated single environmental/spatial variable to the richness orderings for global birds, amphibians and mammals respectively. (b), (e), (h) depicted the most correlated second-order term of environmental/spatial variables to the richness orderings for global birds, amphibians and mammals respectively. (c), (f), (i) depicted the most correlated interaction term of environmental/spatial variables to the richness orderings for global birds, amphibians and mammals respectively.

perature had a strong linear relationship with species richness rankings when compared to the above singlevariable models. For birds, the model for the latitude/ temperature interaction had the adjusted $\mathrm{R}^{2}=0.224 ; \mathrm{P}=$ 0 ; $\mathrm{AIC}=211543.9$. For amphibians, the same model had the adjusted $\mathrm{R}^{2}=0.257 ; \mathrm{P}=0$; $\mathrm{AIC}=185091.7$. For mammals, the model had the adjusted $\mathrm{R}^{2}=0.208 ; \mathrm{P}=0$; AIC $=157174.9$ (Table 2).

\subsection{The Influence of Second-Power Terms of Environmental and Spatial Variables}

I found that the second-order effect has a better fit compared to first-order terms of the variables across dif- ferent taxonomic groups. For birds, the model for the second power of latitude had adjusted $\mathrm{R}^{2}=0.142 ; \mathrm{P}=0$; AIC $=216006$. For amphibians, the model for the second power of latitude had adjusted $\mathrm{R}^{2}=0.356 ; \mathrm{P}=0$; AIC = 179543.8. For mammals, the model for the second power of latitude had adjusted $\mathrm{R}^{2}=0.293 ; \mathrm{P}=0 ;$ AIC $=$ 152331.7 (Table 2).

\section{DISCUSSION}

It has been widely studied on the relationship of species richness and environmental determinants at either global or regional scales [1-3,11]. However, my study represented the first attempt to unravel the roles of inter- 
action and high-order powers of environmental variables on influencing species richness ranking at global scales. My results showed that the inclusion of the terms accounted for interaction and high-order powers of environmental variables could offer new insights on the relationship between environment and species richness.

Firstly, when comparing either spatial or environmental variables, I identified that latitude was the most prevailing variable affecting species richness rankings. This result suggested that at global scale, space, rather than environment, is the most important mechanism regulating global bird, amphibian and mammalian richness rankings. It is a long-term debate which, environment or space, plays a more important role in structuring ecological communities [5,12-15], and there is a lot of literature contributing to the debate. From my understanding for the rankings of global species richness, I found that space is much influential than environment.

However, my finding is not idiosyncratic. There were a couple of broad-scale works stressing the importance of space in shaping species diversity. For example, Cooper et al. [15] also found that spatial effects played a key role in determining conservative niches of global mammals when compared to environmental niches and phylogenetic history. More importantly, the influence of space is mostly attributed to the effect of latitudinal gradients, which has been well recognized on its importance on shaping community structure and species diversity patterns across various taxa and spatial scales [16].

Secondly, when only considering the impact of each of environmental variables (not discussing the role of spatial variables), the greater influence of precipitation compared to temperature was observed. This finding was incongruent with the work [1], which found that all the vertebrate groups except reptiles were jointly constrained by both temperature and precipitation at either global or regional scales. Of course, the consistent aspect is that elevation was found unimportant in both the present and the previous works.

The role of precipitation actually has been observed for many taxa across different spatial scales. For example, at the perspective of species populations, a recent work on an endemic shrub in Patagonian steppe showed that precipitation was much more important to determine its phylogeographic pattern [17]. At local scales for microarthropods, Starzomski et al. [18] found that wet seasons could determine the high abundance and richness of mites in southwestern Canadian areas. When the season turns to the drought period, the mite diversity was significantly reduced. At regional scales of central North American grasslands, Adler and Levine [19] found that plant richness increased significantly with annual precipitation. Moreover, when checking temporal fluctuating spectrum of species richness, it could increase most in wet years rather than dry years. Another work on dung beetle diversity in a Brazilian semi-arid ecosystem also confirmed the assertion that wet seasons could remarkably increase species diversity [20]. To sum up, all these evidences stressed the importance of water availability on influencing species diversity and community structure. At the worldwide scale, I further proved that precipitation, rather than temperature, better determined vertebrate richness rankings if not considering the interactions among the independent variables and the role of spatial variables (latitude and longitude).

However, the above story could run into an opposite direction completely. When I analyzed the interaction and second-power effect of spatial variables and environmental variables, the influence of temperature became emerging. The interaction between latitude and temperature actually had the lowest AIC value for birds; second lowest for amphibians. With regard to second-power effects of variables, the second-power models for latitude the lowest AIC values for amphibians and mammals (Table 2). Thus, my finding strongly supported the importance of interaction and second-order effects among various environmental and spatial variables in determineing global diversity patterns.

The importance of temperature was also well documented, especially from broad-scale perspective when compared to the effect of precipitation. For example, Wang et al. [21] found that tree diversity was largely dependent on temperature conditions in both East Asia and North America territories. Yasuhara [22] stressed the importance of temperature in shaping marine zooplankton distribution along the latitudinal gradient from a historical and geological view. Tittensor et al. [23] found that temperature was the only predictor of marine biodiversity across taxa.

From the perspective of my study, I found that temperature alone could not have impacts on structuring worldwide vertebrate richness ranking patterns at all, but when interacting with global latitudinal gradient, the influence of temperature rose up, especially for birds. Further, the second-power term of latitude has greater impacts on species richness rankings when compared to the influence of the sole latitude, precipitation and their interaction. The second-order term of latitude was the principal determinants of amphibian and mammalian richness rankings (Figure 1, Table 2).

These results were the key novelty in my study, suggesting that one should consider the interaction and highorder effects of independent variables when related them to species diversity patterns. All previous broad-scale works could only observe the independent roles of precipitation, temperature or latitude on shaping species diversity, but none took their interactions and high-order terms into account (but see [24]). 
Thirdly, metabolic theory of ecology [25] predicts that the log-transformed species number should be negatively correlated with the temperature in terms of $1 /(k T)$ in linear form $[24,26,27]$. Here $k$ is the Boltzmann constant and $T$ is the temperature in Kelvins [26]. However, it is not clear for the species richness ranking would also follow this physical prediction. Here by examining global richness rankings of amphibians, birds and mammals across global scales I found that since temperature solely was not a key determinant of species richness ranking when fitting either linear or exponential relationships, the combined effect of Boltzmann constant and absolute temperature should be unimportant as well. Thus, I inferred that metabolic theory did not apply to the situation of species richness rankings, which was in line with empirical tests of temperature-richness relationships [27, 28].

Lastly, although richness ranking is a rough proxy to infer the relationship between environment, space and true species richness, the inclusion of high-order and interaction terms should be valuable to determine the nonlinear effects of environmental and spatial variables. Thus, I argue that for better quantifying the roles of environment and space on determining global diversity patterns, I should adopt high-order and interaction terms so as to better capture the influences caused by the nonlinearity properties of environments and space at different spatiotemporal scales.

\section{ACKNOWLEDGEMENTS}

This work is supported by China Scholarship Council.

\section{REFERENCES}

[1] Qian, H. (2010) Environment-richness relationships for mammals, birds, reptiles and amphibians at global and regional scales. Ecological Research, 25, 629-637. http://dx.doi.org/10.1007/s11284-010-0695-1

[2] Qian, H. and Ricklefs, R.E. (2012) Disentangling the effects of geographic distance and environmental dissimilarity on global patterns of species turnover. Global Ecology and Biogeography, 21, 341-351. http://dx.doi.org/10.1111/j.1466-8238.2011.00672.x

[3] Jetz, W. and Fine, P. (2012) Global gradients in vertebrate diversity predicted by historical area-productivity dynamics and contemporary environment. PLoS Biology, 10, e1001292. http://dx.doi.org/10.1371/journal.pbio.1001292

[4] Hawkins, B.A., McCain, C.M., Davies, T.J., Buckley, L. B., Anacker, B.L., Cornell, H.V., Damschen, E.I., Grytnes, J.-A., Harrison, S., Holt, R.D., et al. (2012) Different evolutionary histories underlie congruent species richness gradients of birds and mammals. Journal of Biogeography, 39, 825-841. http://dx.doi.org/10.1111/j.1365-2699.2011.02655.x

[5] Legendre, P. (1993) Spatial autocorrelation: Trouble or new paradigm? Ecology, 74, 1659-1673. http://dx.doi.org/10.2307/1939924

[6] Storch, D., Keil, P. and Jetz, W. (2012) Universal speciesand endemic-area relationships at continental scales. $\mathrm{Na}$ ture, 488, 79-81. http://dx.doi.org/10.1038/nature11226

[7] Grenyer, R., Orme, C.D.L., Jackson, S.F., Thomas, G.H., Davies, R.G., Davies, T.J., Jones, K.E., Olson, V.A., Ridgely, R.S., Rasmussen, P.C., et al. (2006) Global distribution and conservation of rare and threatened vertebrates. Nature, 444, 93-96.

http://dx.doi.org/10.1038/nature05237

[8] Vieira, C., Blmires, D., Diniz-Fiho, J., Bini, L. and Rangel, T. (2008) Autoregressive modelling of species richness in the Brazilian Cerrado. Brazilian Journal of Biology, 68, 233-240.

http://dx.doi.org/10.1590/S1519-69842008000200003

[9] Chen, Y. (2013) An autoregressive model for global vertebrate richness rankings: Long-distance dispersers could have stronger spatial structures. Zoological Studies, In Press.

[10] R Development Core Team (2011) R: A language and environment for statistical computing, Vienna, Austria. http://www.R-project.org

[11] Qian, H., Wang, X., Wang, S. and Li, Y. (2007) Environmental determinants of amphibian and reptile species richness in China. Ecography, 30, 471-482.

[12] Griffith, D. and Peres-Neto, P. (2006) Spatial modeling in ecology: The flexibility of eigenfunction spatial analyses. Ecology, 87, 2603-2613.

http://dx.doi.org/10.1890/0012-9658(2006)87[2603:SMI ETF]2.0.CO;2

[13] Belmaker, J. and Jetz, W. (2011) Cross-scale variation in species richness-environment associations. Global Ecology and Biogeography, 20, 464-474. http://dx.doi.org/10.1111/j.1466-8238.2010.00615.x

[14] Belmaker, J. and Jetz, W. (2012) Regional pools and environmental controls of vertebrate assemblages. American Naturalist, 179, 512-523.

http://dx.doi.org/10.1086/664610

[15] Cooper, N., Freckleton, R.P. and Jetz, W. (2011) Phylogenetic conservatism of environmental niches in mammals. Proceedings of the Royal Society B: Biological Sciences, 278, 2384-2391. http://dx.doi.org/10.1098/rspb.2010.2207

[16] Kissling, W.D., Sekercioglu, C.H. and Jetz, W. (2012) Bird dietary guild richness across latitudes, environments and biogeographic regions. Global Ecology and Biogeography, 21, 328-340. http://dx.doi.org/10.1111/j.1466-8238.2011.00679.x

[17] Cosacov, A., Johnson, L., Paiaro, Cocucci, A., Cordoba, F. and Sersic, A. (2012) Precipitation rather than temperature influenced the phylogeography of the endemic shurb Anarthrophyllum desideratum in the Patagonian steppe. Journal of Biogeography, 40, 168-182. http://dx.doi.org/10.1111/j.1365-2699.2012.02776.x

[18] Starzomski, B.M., Parker, R.L. and Srivastava, D.S. (2008) On the relationship between regional and local species richness: A test of saturation theory. Ecology, 89, 1921- 
1930. http://dx.doi.org/10.1890/07-0418.1

[19] Adler, P. and Levine, J. (2007) Contrasting relationships between precipitation and species richness in space and time. Oikos, 116, 221-232.

http://dx.doi.org/10.1111/j.0030-1299.2007.15327.x

[20] Liberal, C.N., de Farias, Â.M.I., Meiado, M.V., Filgueiras, B.K.C. and Iannuzzi, L. (2011) How habitat change and rainfall affect dung beetle diversity in Caatinga, a Brazilian semi-arid ecosystem. Journal of Insect Science, 11, 1-11. http://dx.doi.org/10.1673/031.011.11401

[21] Wang, Z., Brown, J., Tang, Z. and Fang, J. (2009) Temperature dependence, spatial scale and tree species diversity in eastern Asia and North America. PNAS, 106, 13388-13392. http://dx.doi.org/10.1073/pnas.0905030106

[22] Yasuhara, M., Hunt, G., Dowsett, H.J., Robinson, M.M., Stoll, D.K. and Marshall, D. (2012) Latitudinal species diversity gradient of marine zooplankton for the last three million years. Ecology Letters, 15, 1174-1179. http://dx.doi.org/10.1111/j.1461-0248.2012.01828.x

[23] Tittensor, D.P., Mora, C., Jetz, W., Lotze, H.K., Ricard, D., Berghe, E. Vanden and Worm, B. (2010) Global patterns and predictors of marine biodiversity across taxa. Nature, 466, 1098-1011. http://dx.doi.org/10.1038/nature09329

[24] Simova, I., Storch, D., Keil, P., Boyle, B., Phillips, O. and Enquist, B. (2011) Global species-energy relationship in forest plots: Role of abundance, temperature and species climatic tolerances. Global Ecology and Biogeography, 20, 842-856. http://dx.doi.org/10.1111/j.1466-8238.2011.00650.x

[25] Brown, J., Gillooly, J., Allen, A., Savage, V. and West, G. (2004) Toward a metabolic theory of ecology. Ecology, 85, 1771-1789. http://dx.doi.org/10.1890/03-9000

[26] Storch, D. (2012) Biodiversity and its energetic and thermal controls. In: Sibly, R., Brown, J., and KordricBrown, A., Eds., Metabolic Ecology: A Scaling Approach, John Wiley \& Sons, Ltd., Chichester. http://dx.doi.org/10.1002/9781119968535.ch11

[27] Algar, A., Kerr, J. and Currie, D. (2007) A test of metabolic theory as the mechanism underlying broad-scale species-richness gradients. Global Ecology and Biogeography, 16, 170-178. http://dx.doi.org/10.1111/j.1466-8238.2006.00275.x

[28] Hawkins, B.A., Albuquerque, F.S., Araujo, M.B., Beck, J., Bini, L.M., Cabrero-Sañudo, F.J., Castro-Parga, I., DinizFilho, J.A.F., Ferrer-Castan, D., Field, R., et al. (2007) A global evaluation of metabolic theory as an explanation for terrestrial species richness gradients. Ecology, 88, 1877-1888. http://dx.doi.org/10.1890/06-1444.1 